\title{
O Mérito nos Processos de Seleção da Alta Direção da Administração Pública Portuguesa: mito ou realidade? ${ }^{1}$
}

\author{
João Bilhim²
}

Resumo: A influência do modelo gestionário na reforma administrativa em Portugal e, em particular, no que se refere à introdução de maior racionalidade técnica nos processos de gestão pública é amplamente reconhecida em Portugal. Foram muitos os governos que, nos países da OCDE, tomaram iniciativas idênticas. Todavia, a literatura sobre a reforma administrativa apresenta bastante evidência da resiliência das burocracias institucionais à mudança. Acontece que a NPM quis afirmar-se como uma receita padrão sem respeito pela diversidade cultural das diversas administrações e, apesar de se assumir como cartilha, obteve diferentes expressões e manifestações. Este artigo quer contribuir para este debate. Por isso, examina a influência da meritocracia, como ideia do NPM, na reforma administrativa de Portugal.

Palavras-chave: Mérito. Recrutamento e seleção. Dirigentes superiores.

\begin{abstract}
The influence on managerial model of administrative reform in Portugal and in particular with regard to the introduction of higher technical rationality in the processes of public management is widely recognized in Portugal. There were many governments in OECD countries have taken similar initiatives. However, the literature on administrative reform presents enough evidence of the resilience of institutional bureaucracies to change. It turns out that the NPM would assert itself as a standard recipe without respect for cultural diversity and the various administrations, despite taking over as primer, got different expressions and manifestations. This article aims to contribute to this debate. Therefore, examines the influence of meritocracy, as NPM idea, administrative reform of Portugal.
\end{abstract}

Key words: Merit. Recruitment and selection. Senior managers.

1 Texto aceito para o XVII Congresso Internacional do CLAD sobre a Reforma do Estado e da Administração Pública.

2 Doutor em Ciências Sociais pela Universidade Técnica de Lisboa (UTL) (1993). Atualmente é presidente da Comissão de Recrutamento e Seleção da Administração Pública e professor catedrático da Universidade Técnica de Lisboa. E-mail: bilhim@ iscsp.utl.pt.

Recebido em: 23/06/2012.

Revisado em: 15/07/2012.

Aprovado em: 10/08/2012. 


\section{Introdução}

A meritocracia é hoje valorizada e aceite como sinal de modernidade, garantia ética, baluarte contra a corrupção, e garantia de imparcialidade na gestão das pessoas no setor público. Todavia, nem sempre foi assim.

$\mathrm{Na}$ origem, o termo "meritocracia" apresentava um pecado original e era pejorativamente identificado. De fato, quando o vocábulo "meritocracia" foi inventado (meritus + cracia), isto é, um vocábulo composto de uma palavra latina e, outra grega significando poder/domínio do mérito, por Michael Young, em 1958, na obra "Rise of the Meritocracy", o seu autor quis dar-lhe um sentido oposto ao atual.

Michael Young atribuiu um sentido negativo ao termo, já que a história que o seu livro contava dizia respeito a uma sociedade futura na qual a posição social na estrutura de poder era determinada pelo coeficiente intelectual e pelo esforço do sujeito. Young achava isso reprovável e utilizou o termo meritocracia num sentido depreciativo, diferente do atribuído pelo autor desta comunicação.

Para a sociologia contemporânea, a meritocracia corresponde a um sistema em que as posições sociais são preenchidas com base no mérito individual e não em virtude de critérios como a riqueza, o sexo, a origem social ou a cor do partido político em que se milita.

Salienta-se que Weber (1978), ao identificar as características da burocracia, referia, entre oito traços, os três seguintes: organização cuja seleção dos funcionários se faz com base no mérito; baseada na separação entre proprietários e gestores; que se caracteriza pela profissionalização dos seus funcionários.

$\mathrm{Na}$ análise da literatura atual do modelo gestionário, os termos meritocracia/meritocrático/mérito, numa ligeira análise de conteúdo, aparecem, quer na literatura científica, quer nas recomendações de diversos organismos internacionais como a OCDE/PUMA e o Banco Mundial, entre outros, com muita frequência. 
Neste ponto, vale a pena, em primeiro lugar, chamar a atenção para o paralelismo entre Michael Young e Weber: ambos, em épocas diferentes, estão fundamentalmente preocupados com o estudo das manifestações de um processo mais geral de racionalização, que ocorre na sociedade como um todo.

Ambos, realçam a relação entre os meios e os fins, circunstância que confere à burocracia um carácter racional; ambos predizem a existência de um "tipo ideal" (ideal type) de organização burocrática com a presença do mérito como grande divisor de águas na estrutura de poder das sociedades e das organizações.

A diferença é que Weber identifica o mérito, isto é, distingue-o de outras formas, atribui-lhe valor e confere-lhe um interesse positivo, ao contrário do que faz Michael Young.

Em segundo lugar, importa salientar uma contradição significativa. Se, por um lado, a NPM se afirma como cartilha que combate a burocracia weberiana, por outro, adota o seu conceito de mérito e impõe a sua prática às diversas administrações, independentemente da cultura dos povos no seio da qual tais administrações existam.

Acresce que, nos países da "Europa das oliveiras" ou Europa do Sul, não há, propriamente, vozes que se levantem na Administração Pública contra o mérito, porque tal não seria politicamente correto, quer à luz da burocracia de Weber quer por força das boas práticas em usos nos países da OCDE. Todavia, persiste uma postura cultural pesada, marcada pela postura cultural segundo a qual “[...] a administração é para mim e para os meus". Por isso, se não será difícil cruzar-se com acirrados defensores do valor do mérito, mais difícil será encontrar, em suas vidas, coerência com tal postulado. Algo do estilo "[...] quem tem necessidade de ter em conta o mérito são os outros, para mim, basta-me ser eu a escolher e o mérito brota como brota de fonte cristalina a água em tórrido estio". Existe em Portugal algo que metaforicamente se chamaria de esquizofrenia cultural: afirmo uma coisa e pratico o seu contrário.

De fato, a "Europa das oliveiras" ou produtora de azeite é, culturalmente, diferente da Europa da manteiga, ou seja, da Europa do Norte. 
Para a Europa do Sul, produtora de azeite, não basta apenas a afirmação de um valor ou princípio para que algo aconteça; importa que tal valor ou princípio seja transformado em traço de cultura no interior da administração pública. Há aqui maior hierarquização e formalização, confundindo-se os processos de liderança com o mero exercício de autoridade. Neste caldo de cultura administrativa, o "deve ser" confunde-se com o "é": O primeiro beneficiário da Administração é o próprio dirigente ou funcionário, seguido dos familiares e amigos e só depois chegam os outros. Ora, aqui reside o problema de Portugal na sua difícil relação com o mérito como critério último da escolha dos dirigentes.

Por isso, o fato de Portugal, pertencer a esta Europa que produz azeite e adotar, pela primeira vez, na sua milenar história, um regime de recrutamento e seleção por concurso público para a alta direção (dirigentes colocados na hierarquia da Administração imediatamente abaixo do membro do Governo), promovido por uma entidade administrativa independente cuja missão é garantir o mérito dos candidatos é algo merecedor de atenção e de análise aprofundada.

Nos termos dos Estatutos da Comissão de Recrutamento e Seleção para a Administração Pública (CReSAP) em Portugal, esta não pede nem recebe orientações dos Governos na prossecução dos seus fins (artigo $5^{\circ}$ da Lei n. 64/2011, de 22 de Dezembro). A CReSAP responde perante o Parlamento. É, na prática e na teoria, uma agência independente e ela em si mesmo já expressa outra das ideias do modelo gestionário - a agencificação das estruturas da Administração. (ARAÚJO, 2002)

A CreSAP é responsável pela introdução da meritocracia na estrutura da Administração Central do Estado (direções-gerais e subdiretores-gerais, presidente e vogais de institutos públicos) através da introdução de procedimentos concursais isentos e autônomos do Governo. Acresce que a CReSAP ainda é responsável pela elaboração de relatórios de avaliação do mérito dos gestores públicos, através da avaliação curricular e de adequação de perfil. 


\section{Os Processos de Recrutamento e Seleção da CReSAP}

O estatuto do pessoal dirigente dos serviços e órgãos da administração central, local e regional do Estado, com a alteração decorrente da Lei n. 64/2011, de 22 de dezembro, veio estabelecer, para o recrutamento e seleção dos titulares dos cargos de direção superior, de $1^{\circ}$ e de $2^{\circ}$ grau, um procedimento concursal a efetuar pela Comissão de Recrutamento e Seleção para a Administração Pública (CReSAP), mediante iniciativa do membro do Governo com poder de direção ou de superintendência e tutela sobre o serviço ou órgão em que se integra o cargo a preencher e de acordo com a tramitação prevista nos seus artigos 18 e 19 .

Acresce que a Lei-Quadro dos institutos públicos, com a alteração operada pelo Decreto-Lei n. 5/2012, de 17 de janeiro, veio alargar a obrigatoriedade daquela metodologia de recrutamento e seleção, assente em procedimento concursal efetuado pela CReSAP, ao recrutamento e seleção dos titulares do órgão de direção dos institutos públicos de regime comum, que passaram assim a ser abrangidos, neste âmbito e subsidiariamente, por aquele estatuto do pessoal dirigente.

Já do ponto de vista das entidades públicas excecionadas da aplicação do referido estatuto do pessoal dirigente dos serviços e órgãos da administração central, local e regional do Estado, incluindo das regras aplicáveis no recrutamento e seleção de titulares para cargos de direção superior, dispõe o artigo $1^{\circ}$ do estatuto que não se aplica aos cargos dirigentes:

Dos órgãos e serviços de apoio ao Presidente da República, à Assembleia da República e aos tribunais.

Das Forças Armadas, das forças e serviços de segurança dos órgãos públicos que exercem funções de segurança interna, nos termos definidos pela Lei de Segurança Interna, bem como do Sistema de Informações da República Portuguesa e do serviço que tenha por missão assegurar a gestão do sistema prisional.

Dos órgãos de gestão dos estabelecimentos de ensino. 
Dos órgãos de gestão dos estabelecimentos do setor público administrativo da saúde.

Do Ministério dos Negócios Estrangeiros que, por força de disposição legal própria, tenham de ser providos por pessoal da carreira diplomática ou para cujo provimento tenha sido escolhido pessoal da mesma carreira ou que sejam exercidos nos serviços externos.

Integrados em carreiras.

Acontece que, no âmbito da lei-quadro dos institutos públicos, encontra-se consagrada a possibilidade dos institutos públicos gozarem de regime especial, com derrogação do regime comum na estrita medida necessária à sua especificidade, nos termos definidos pelos diplomas que aos mesmos respeitem, pelo que também nestes casos se pode verificar a aplicação de regime de recrutamento e seleção diverso do procedimento concursal de recrutamento e seleção de titulares para os cargos de direção superior. Indicam-se os seguintes tipos de institutos públicos de regime especial:

As universidades e escolas de ensino superior politécnico.

As instituições públicas de solidariedade e segurança social.

Os estabelecimentos do Serviço Nacional de Saúde.

As entidades administrativas independentes.

O conjunto de institutos públicos elencados no n. 3 do artigo 48 da referida Lei-Quadro, ainda que os respetivos diplomas orgânicos não determinem, em regra, um regime diverso daquele que decorre da aplicação subsidiária do estatuto do pessoal dirigente dos serviços e órgãos da administração central, local e regional do Estado.

Ora, de acordo com o expresso nos artigos 12 e 13 do estatuto do gestor público, aprovado pelo Decreto-Lei n. 71/2007, de 27 de março, alterado pela Lei n. 64 -A/2008, de 31 de dezembro, e pelo Decreto-Lei n. 8/2012, de 18 de janeiro, e retificado pela Declaração de Retificação n. $2 / 2012$, de 25 de janeiro, encontra-se estabelecido, desde o Decreto-Lei n. 8/2012, de 18 de janeiro, um novo sistema de recrutamento e seleção dos gestores públicos, por força do qual a CReSAP está incumbida 
de elaborar uma avaliação, não vinculativa, do currículo e adequação das competências ao cargo de gestor público, da personalidade a que respeita a proposta de designação.

Resumindo, a CReSAP intervém nos processos de recrutamento e seleção, em síntese, elaborando pareceres de avaliação curricular e de adequação de competências no caso dos gestores públicos e efetuando procedimentos concursais de recrutamento e seleção no caso dos dirigentes superiores da administração direta e indireta do Estado.

A CReSAP entende por "procedimento concursal" o conjunto de operações que visa a ocupação de cargos de direção superior necessários ao desenvolvimento das atividades e à prossecução dos objetivos de órgãos ou serviços; por "recrutamento" o conjunto de procedimentos que visa atrair candidatos potencialmente qualificados, para o desempenho do cargo; por "seleção" o conjunto de operações que, mediante a utilização de métodos e técnicas adequados, permite avaliar os candidatos de acordo com as competências indispensáveis à execução das atividades inerentes ao cargo a prover; por "métodos de seleção" o conjunto das técnicas específicas de avaliação da adequação dos candidatos às exigências do cargo a prover, tendo como referência um perfil de competências previamente definido; por "mérito" a adequação do conjunto de atributos exigidos para um bom desempenho do cargo em causa.

\subsection{Recrutamento por Concurso}

A iniciativa do procedimento concursal cabe ao membro do Governo com poder de direção ou de superintendência e tutela sobre o serviço ou órgão em que se integra o cargo a preencher, competindo-lhe, neste âmbito, definir genérica e fundamentadamente o perfil, experiência profissional e competências de gestão exigíveis aos candidatos e elaborar a respetiva Carta de Missão.

Identificada a necessidade de recrutamento, o júri designado pelo Presidente da CReSAP estabelece os critérios aplicáveis na seleção de candidatos a cargos de direção superior, designadamente as competências de liderança, colaboração, motivação, orientação estratégica, orientação para resultados, orientação para o cidadão e serviço público, gestão da 
mudança e inovação, sensibilidade social, experiência profissional, formação académica, formação profissional e aptidão. Na sequência da definição de perfis, será publicitada a abertura do procedimento concursal.

Nos procedimentos concursais, o recrutamento é aberto interna e externamente, podendo, assim candidatar-se quem não possua qualquer vínculo laboral à Administração, tendo como constrangimentos apenas a cidadania portuguesa e serem os candidatos detentores de licenciatura, respetivamente há 12 e 8 anos, (Graduação), conforme se trate de cargo superior de $1^{\circ}$ ou $2^{\circ}$ grau.

A publicação integral contém, designadamente, os seguintes elementos:

a) identificação do ato que autoriza o procedimento e da entidade que o realiza;

b) carta de missão;

c) identificação do cargo de direção superior a ocupar e da respetiva modalidade da relação jurídica de emprego público a constituir;

d) duração da comissão de serviço e respetiva renovação;

e) exclusividade de funções;

f) remuneração a auferir;

g) identificação do local de trabalho em que as funções vão ser exercidas;

h) as competências referidas nos artigo $6^{\circ}$ e $7^{\circ}$ do Estatuto do Pessoal Dirigente;

i) grau académico e número de anos da sua titularidade;

j) área de formação adequada ao perfil;

k) área de especialização, quando constante do perfil definido;

1) requisitos legais especialmente previstos para a titularidade do cargo;

m) forma e prazo de apresentação da candidatura;

n) endereço eletrônico onde deve ser apresentada a candidatura; 
o) métodos de seleção e critérios a utilizar;

p) composição e identificação do júri;

q) a referência a que em qualquer fase do procedimento pode o júri solicitar junto dos candidatos a entrega dos documentos comprovativos dos fatos por si alegados;

r) indicação de que as candidaturas são apresentadas, exclusivamente, por via eletrônica.

O recrutamento faz-se por meio de anúncios no Diário da República e em mais quatro plataformas eletrônicas obrigatoriamente na base de dados de emprego público (BEP), na CReSAP, no Portal do Governo e em mais uma plataforma privada.

\subsection{Seleção por Concurso Público}

A seleção visa escolher, de entre os candidatos atraídos pelo recrutamento, a pessoa certa para o lugar certo, envolvendo as seguintes fases: triagem das candidaturas, entrevistas, provas de competências, em casos especiais testes e decisão final sobre a escolha.

A seleção, nos casos de concurso, processa-se totalmente em suporte eletrônico numa plataforma especificamente desenvolvida para este caso. Os candidatos deixaram na plataforma os seguintes elementos: currículo no repertório de currículos da CReSAP identificado pelo número de identificação fiscal (NIF); preenchimento do formulário do questionário de autoavaliação que compreende os seguintes 12 critérios: competências de liderança, colaboração, motivação, orientação estratégica, orientação para resultados, orientação para o cidadão e serviço público, gestão da mudança e inovação, sensibilidade social, experiência profissional, formação académica, formação profissional e aptidão.

A triagem inicia-se com a análise da resposta dada pelos opositores ao concurso relativamente aos 12 critérios.

O Curriculum Vitae (CV) deve espelhar a reflexão que o candidato faz da sua experiência passada, na relação com o posto de trabalho para o qual concorre. Na triagem, o júri deve ter muito bem presente a avaliação dessa relação. Pode haver CV excelentes em si e nada relevantes para o 
caso em concreto. Por isso, importa ter em conta a resposta dada ao questionário de autoavaliação.

São critérios de desempate, para a designação dos seis candidatos que passam para a fase seguinte, respetivamente, a nota mais elevada e a maior antiguidade como licenciado.

Terminada a avaliação curricular pelo júri, este reúne e ordena os candidatos com uma classificação de zero a vinte.

Dessa ordenação resulta que irão, em princípio a entrevista apenas os primeiros seis mais bem classificados. Isto porque, como o júri tem de apresentar três candidatos ao membro do governo para ele escolher um, as boas práticas recomendam que se entreviste o dobro do número a selecionar.

São submetidos à fase da entrevista de avaliação até seis candidatos objeto de avaliação curricular. A escolha dos candidatos referidos é efetuada de acordo com a classificação obtida no conjunto dos 12 critérios referidos.

Os candidatos selecionados para a realização da entrevista de avaliação são convocados, através do endereço eletrônico indicado na candidatura, com cinco dias úteis de antecedência da data marcada para a prova de competências e entrevista de avaliação.

A entrevista de avaliação é composta: a) pela avaliação de competências, a qual é integrada por um conjunto de provas que permitem identificar o perfil de competências do candidato; b) pela entrevista pessoal que consiste numa análise estruturada e aprofundada dos critérios previstos no número 2 do artigo $6^{\circ}$ sustentada pela descrição de comportamentos ocorridos em situações reais e vivenciadas pelo candidato.

As provas de competências procuram medir uma determinada capacidade, por exemplo, a criatividade e imaginação, determinação, individualidade, boa vontade, autoconfiança, paciência, reflexão, persistência, capacidade de adaptação, perfecionismo, sensibilidade (perspicácia), entre outras. 
Para esta prova, a CreSAP segue o modelo da Thomas Internacional relativamente ao perfil pessoal e à análise do cargo, salientando-se os quatro fatores do perfil: domínio (poder); influência (pessoas); estabilidade (ritmo); conformidade (regras). Com esses quatro fatores são construídos quatro tipos puros de perfil de dirigente inspirado nos tipos psicológicos de Jung. O resultado da prova de competências não serve para excluir, nem avaliar autonomamente os candidatos. Tem por finalidade apenas informar os membros do júri ou banca responsável pela entrevista sobre o perfil dos candidatos em análise. Só em sede de entrevista, ou seja, de júri ou banca é que cada membro valorará como entender a informação obtida através da prova de competências.

A entrevista de avaliação é conduzida por um júri ou banca constituída por quatro membros: presidente, vogal permanente, vogal não permanente e um perito. Com a entrevista procura o júri obter, através de uma relação interpessoal, não só informações sobre comportamentos profissionais diretamente relacionados com as competências consideradas essenciais para o exercício do cargo, como clarificar pontos ambíguos do currículo e ainda aprofundar ou detalhar aspetos pertinentes para o diagnóstico do mérito do candidato. A entrevista tem lugar logo após a prova de competências.

A entrevista estruturada possui um guião, em que as perguntas são planeadas, seguindo uma ordem determinada e sendo formuladas nos mesmos termos. Para cada um dos 12 critérios mencionados atrás, há um conjunto de perguntas estandardizadas. Por exemplo, para o critério da orientação estratégicas, as questões a colocar ao candidato são, por exemplo, "quais são para si os maiores desafios que se colocam no cargo para o qual se candidata nos próximos três anos? Descreva-me um evento em que teve de gerir uma situação adversa e de elevado risco para a organização no sentido de obter uma vantagem sustentada. Como procedeu? Que ações levou a cabo? Que resultados obteve?"

A entrevista pessoal possui uma duração de 30 minutos. Por cada entrevista de avaliação é elaborado pelo júri, individualmente ou em conjunto, um parecer qualitativo sobre cada um dos candidatos, que consta da ata final. 
Com base nesta ata, o júri elabora um relatório final, que é remetido ao membro do Governo, através do Presidente da CreSAP, indicando, por ordem alfabética, os três candidatos dos quais, obrigatoriamente, o membro do Governo nomeará um.

\subsection{Seleção sem Concurso: gestores públicos}

A CReSAP no caso dos gestores públicos procede à avaliação curricular e de adequação de perfil das personalidades enviadas pelo Governo com base nos seguintes documentos: currículo profissional elaborado de acordo com o modelo europeu; questionário de autoavaliação; perfil do cargo, por defeito, o que consta do sítio eletrônico www.cresap.pt ou o perfil específico que tenha apresentado o Governo.

Quando o processo de solicitação de parecer dá entrada na CreSAP, o presidente nomeia um relator, responsável pela elaboração do parecer. A Comissão Técnica Permanente (CTP), constituída apenas pelos três vogais permanentes e pelo presidente, decide por unanimidade ou por maioria, a aprovação ou recusa do parecer.

Por princípio, a CTP pronuncia-se sobre cada caso e não sobre o todo (a equipa) do conselho de administração. Todavia por solicitação expressa do Governo, pode a CreSAP integrar no seu parecer esta apreciação adicional.

\subsection{Seleção sem Concurso: dirigentes equiparados}

Na Administração Pública Portuguesa, para além dos casos “típicos", descritos anteriormente, verifica-se a existência de casos "atípicos", ou seja, outras entidades públicas cujos cargos dirigentes possuem caraterísticas "atípicas" face à demais Administração Pública, nomeadamente, identificação, duração de mandato e regimes de recrutamento, entre outros, constatando-se ainda que, em algumas situações, se encontra prevista a equiparação parcial dos titulares desses cargos a dirigentes superiores de $1^{\circ}$ ou $2^{\circ}$ grau, nomeadamente para efeitos remuneratórios. Esses cargos atípicos encontram-se tanto em serviços da administração direta, como 
em institutos públicos de regime comum e de regime especial e outras pessoas coletivas públicas.

Nesses casos, entendeu o Governo manter, de forma coerente, a aplicação dos princípios de transparência, isenção e meritocracia que motivaram a alteração dos modelos de recrutamento e seleção de dirigentes e gestores públicos, até ao completo esclarecimento daquelas "atipicidades", designadamente, através das iniciativas legislativas que se mostrem necessárias.

Acontece que a CReSAP, nos termos da alínea i) do artigo 11 dos seus Estatutos, aprovados pela Lei n. 64/2011, de 22 de dezembro, possui o dever de "[...] cooperar com entidades públicas em matéria de recrutamento e seleção na Administração Pública [...]" e em similitude com a solução que atualmente vigora no processo de designação dos gestores públicos, o Governo passou a solicitar à CReSAP um parecer de avaliação curricular e de adequação de perfil das personalidades a designar para titulares de cargos "atípicos". Tendo o Governo considerado ainda a maior proximidade destes cargos "atípicos" com os cargos de direção superior da Administração Pública, o parecer da CReSAP é vinculativo para o decisor ao contrário do que acontece com os gestores públicos em que o parecer não possui tal caráter.

Nesses casos, o processo administrativo é praticamente igual ao processo dos gestores públicos, avaliação curricular e de adequação de perfil, sem concurso público, mas o parecer é vinculativo do Governo, em virtude destas personalidades se encontrarem equiparadas a dirigentes superiores. Trata-se de titulares de cargos equiparados só para alguns efeitos a dirigentes superiores de $1^{\circ}$ grau, mas que não o são de fato nem de direito, só o sendo, por exemplo, para efeitos de vencimento. Por isso, não estão obrigados a realizar concurso, possuem um regime mais abreviado, semelhante aos gestores das empresas públicas, mas ao contrário deles o parecer da CreSAP é vinculativo para o Governo. 


\section{A Busca do Mérito Será Mito ou Realidade}

O mito é uma realidade cultural extremamente complexa, que pode ser abordada e interpretada através de perspetivas múltiplas e complementares. Toma-se de empréstimo, com a devida vênia, um título de Mircea Eliade, obra marcante na minha formação graduada em filosofia e ciências antropológicas. Todavia, o mito de que aqui de quer falar não corresponde ao da obra "Mito e Realidade". É que, para Mircea Eliade, o mito conta uma história sagrada; ele relata um acontecimento ocorrido no tempo primordial, o tempo fabuloso do "princípio", o que não corresponde ao caso vertente porque usa-se esse termo mais como analogia e aproximação.

Parece existir, entre os acadêmicos que pensam, ensinam e escrevem sobre a Administração Pública e os práticos que nela trabalham, uma espécie de crença generalizada que de alguma forma vai passando de geração em geração ao longo dos tempos sobre uma administração pública ideal em que a corrupção seria totalmente derrotada, o bem triunfaria e o mérito seria a regra na ocupação de todos os cargos e funções na estrutura do Estado. Aliás, a retórica dos partidos políticos, em democracia, ajuda, significativamente, a alimentar esta crença, quer em momentos específicos como são os eleitorais, quer, mais tarde, nas formas de fazer oposição parlamentar.

Essa crença coletiva, em particular nos países do azeite, sul da Europa, apresenta uma contradição enorme: teoricamente não se encontra ninguém que não milite a favor do mérito, mas não se acredita efetivamente no sistema e, em simultâneo, pedem-se favores para a contratação de um familiar ou e um amigo, em detrimento do princípio acabado de militantemente defender. Tratar-se-á de algo "humano demasiado humano", como escreveu Friedrich Nietzsche após o rompimento com o romantismo de Richard Wagner e o pessimismo de Arthur Schopenhauer?

A preocupação por basear no mérito a ocupação dos cargos na estrutura administrativa do Estado é tão antiga como o mandarinato, instituído na China antiga. Os mandarins dividiam-se em duas categorias: a civil e a militar. Cada uma dessas categorias dividia-se em nove graus, 
subdividindo-se cada um destes em duas classes: a dos grandes mandarins e a dos mandarins ordinários.

$\mathrm{O}$ acesso a essa classe privilegiada era feito por concurso, depois de obtidos diferentes graus de conhecimento, progressivamente, mais exigentes. As promoções na carreira eram obtidas por mérito.

Se é certo que Max Weber, no conceito de burocracia como tipo ideal, prescrevia a meritocracia como consequência da evolução social, não é menos certo que o modelo gestionário, desde a década de oitenta do século passado, combatendo o modelo burocrático weberiano de organização do Estado e da Administração Pública, coloca a urgência da introdução de sistemas meritocráticos, como um dos pontos essenciais da sua cartilha.

Ora, aqui colocam-se diversas questões: será que os sistemas burocráticos, dadas as suas disfunções evidenciadas por Merton, falharam na prossecução deste resultado, almejado desde a antiga China? Será que um sistema meritocrático funciona mais, lançando mão da metáfora, como a estrela polar que existe para nos orientar e não para ser atingida? Será que a meritocracia é, antes de tudo, uma posição estratégica que os governos e os administradores públicos tomam e não tanto um objetivo ou meta quantificada?

Nas quatro últimas décadas assistiu-se a uma crítica generalizada ao desempenho da Administração Pública, acusando-a de ser fiel ao modelo weberiano e, consequentemente, de estar em contraciclo com a evolução social, impondo-se a modernização administrativa. Um dos pontos focais dessa reforma seria a introdução do mérito, uma vez que o modelo weberiano falhara a sua concretização.

Muitas vozes denunciaram este estado de coisas caraterizado por: má imagem dos serviços prestados; baixa qualidade; custos excessivos; burocracia e centralização; opacidade aos olhos do cidadão; percepção de que os dirigentes não resolvem os problemas dos cidadãos, mas a sua própria carreira; corrupção; fraca produtividade; falta de recursos qualificados; desmotivação de funcionários; ausência de controlo de custos; ausência de pensamento estratégico e visão; fraca gestão; ausência de um 
sistema meritocrático. Todos os interessados em redor da Administração, desde os sindicatos, empresários, os media, consultores, partidos políticos até o público em geral, pressionaram os governos para que estes reformassem a Administração Pública em virtude de esta ter sido construída com base em princípios errados da burocracia de Max Weber, precisando de ser reinventada e de renovar as suas instituições. (BARZELEY; ARMAJANI, 1992)

Como a ciência da administração pública, embora tendo as suas raízes, fundamentalmente, na teoria organizacional e teoria política, acolhe ainda contributos valiosos de outras ciências sociais e comportamentais, nomeadamente a filosofia e até a teologia, é compreensível que as estratégias da reforma para mudança da Administração Pública, enquadradas no modelo gestionário, tenham proveniência em diversas e diferentes ciências. Aliás, o modelo gestionário integra a nova administração pública (NPM) e a reinvenção da governação que marcou toda a década de noventa do século passado corporizada nas administrações de Bill Clinton nos EUA e de Tony Blair no Reino Unido.

A cartilha do modelo gestionário que, por mimitização, Portugal, entre os muitos países da OCDE, está adotando compreende medidas como: cortes orçamentais, privatizações, rutura entre o financiamento e aprestação, contratualização, vouchers ou cheques diretos aos cidadãos, foco no cliente e não no utente/usuário, fomento da concorrência entre prestadores (privado/público e público/público), gestão flexível, uma reedição da dicotomia de Wilson quanto à relação entre políticos e burocratas, descentralização e desconcentração de serviços, agenciamento, fomento das TICs, maior regulação e menor prestação pelo Estado, avaliação do desempenho e recrutamento por mérito.

Importa reconhecer que se este elenco de novas práticas de gestão não deixa de aparentar um conjunto desgarrado e avulso de medidas embrulhadas por vezes numa estratégia vaga de melhoria da qualidade dos serviços, o certo é que não faltam as ideias de fazer mais com o mesmo orçamento ou fazer o mesmo com menos custos.

Não cabe aqui analisar a fragmentação dos serviços e das estruturas organizacionais da Administração tradicional que esta nova cartilha ges- 
tionária acarretou, a qual teve como consequência o acento colocado mais na gestão de risco e menos na prudência e lei, mais na competição e menos na cooperação e confiança, mais na eficiência e menos na equidade, na proliferação de organismo com naturezas jurídicas diversas e menos no holismo dos organismos públicos, mais no direito privado e menos no direito administrativo. (GREGORY, 2003)

Acontece que a literatura sobre a reforma administrativa é rica em referências relativas à resiliência ou resistência à mudança das instituições, em especial quando as reformas põem em causa as práticas, os processos e os procedimentos culturalmente instituídos. A cultura organizacional, vista como o conjunto de normas, valores e crenças, na sua dimensão mais profunda condiciona os traços culturais mais superficiais, como as rotinas, os processos, as práticas e os sistemas de gestão. Não se reformam umas, as superficiais, sem reformar as outras mais profundas. (BILHIM, 1988)

É aqui que se coloca a questão de saber se as reformas que foram introduzidas em Portugal, através da alteração do estatuto do pessoal dirigente dos serviços e órgãos da administração central, local e regional do Estado, com a Lei n. 64/2011, de 22 de dezembro, tendo em vista a introdução de um processo ou prática de gestão pública que garanta o mérito, será mito ou realidade.

A questão é mesmo mais profunda: será que as novas normas e práticas de gestão pública contribuem para uma mudança mais profunda da cultura relativamente aos valores e às crenças? Será que a relação não se comporta de forma linear: o superficial, as práticas e normas da gestão contribuem para a mudança do nível mais profundo da cultura e a mudança operada a este nível também atua sobre o nível ou camada mais superficial? Esse parece ser o desafio com que a Administração Pública portuguesa se encontra confrontada com a iniciativa política de reformar a Administração através da introdução de um novo sistema de recrutamento e seleção dos dirigentes de topo de todo a aparelho do Estado. 


\section{Conclusões}

O objetivo deste artigo era analisar, no contexto da reforma administrativa em Portugal, se o novo sistema de recrutamento e seleção da alta direção, previsto na Lei n. 64/2011, de 22 de dezembro, é mito ou realidade. Nele apresentam-se o estado da arte sobre a reforma administrativa e o contributo do modelo gestionário em Portugal, tomando em linha de conta o esforço de racionalização que este modelo contempla e destacando o mérito, de entre o rol de medidas que compõem o modelo gestionário. Foi descrito o sistema de recrutamento e seleção, contido na lei que alterou o estatuto jurídico dos dirigentes da Administração Central, Regional e Local e foram levantadas algumas contradições e problemas que se prendem com a implementação de sistemas de gestão na sua relação com a cultura administrativa.

Afigura-se clara a influência que o modelo gestionário teve na reforma administrativa em Portugal e, em particular, no que se refere à introdução de maior racionalidade na despesa pública, na qualidade de serviço e no esforço por garantir o triunfo do mérito através da introdução de um procedimento concursal ou através da avaliação curricular e de adequação de perfil levado a cabo por uma entidade administrativa independente, a CReSAP.

Por outro lado, parece não restar dúvidas de que o caminho a seguir não poderá ser o da pressão das organizações internacionais nomeadamente da OCDE PUMA, tendo em vista cada País aplicar todo o conjunto de reformas de uma só vez e sem ter em linha de conta os seus traços culturais e, em particular, os da sua administração. A experiência portuguesa recomenda que se encare o menu de proposta de reforma do modelo gestionário e dele, tal como acontece num restaurante, cada país escolha aquilo que, no momento, é capaz de fazer com sucesso em matéria de reforma (POLLIT; BOUCKAERT, 2000).

Relativamente aos ganhos obtidos com as reformas administrativas em Portugal, não há estudos com dados fiáveis. Aliás, no estrangeiro, “[...] não há dados disponíveis fiáveis em nenhum país, sobre as poupanças que as reformas produziram” (KETTL, 2005, p. 51). Todavia, é certo 
que em Portugal houve redução de custos com pessoal e no volume de contratação, tendo-se reduzido desde o Programa PRACE, em 2006 até à presente data, cerca de trezentos mil funcionários, muitos dos quais, é certo, através de processos de reforma ou aposentação e através de rigorosa limitação de novas contratações. Neste mesmo período, em Portugal, procedeu-se a cortes em cerca de $50 \%$ de organismos e departamentos intermédios, sendo o número de dirigentes superiores e intermédios cortados em igual taxa.

Acontece que, muitas vezes, a avaliação da reforma - e isso é claramente visível no caso do recrutamento por mérito através de concurso público - é uma mera avaliação da representação mental dos atores sociais, uma impressão subjetiva do impacto de certas medidas. Todavia, isto não significa que não haja resultados ou melhorias em Portugal. A confirmá-lo está o fato de, em Portugal, há cerca de 30 anos, a Administração Pública possuir e aplicar, de forma mais ou menos sistemática, com periodicidade anual, um sistema de avaliação do mérito dos funcionários; há cerca de dez anos introduzir o sistema concursal interno para o recrutamento dos dirigentes intermédios e agora os dirigentes de topo que, sempre na história administrativa de Portugal foram escolha régia ou dos eleitos do povo, governantes do País, passarem a ser selecionados em concurso público.

Só o futuro dirá se os atuais membros da CreSAP, como entidade administrativa independente, estão à altura de liderar este desafio de provocar, através das suas práticas, processos e sistemas de gestão, mudanças na camada mais profunda da cultura administrativa de Portugal, nomeadamente nos valores e as crenças. É que, se for atingida esta camada, estará garantido o triunfo do mérito e provado que se os valores condicionam as práticas de gestão, estas também condicionam aqueles.

\section{Referências}

ARAÚJO, Joaquim Filipe Ferraz Esteves. NPM and the Change in Portuguese Central Government, International Public Management Journal, Thousand Oaks/US, v. 5, n. 3, p. 223-236, 2002. 
BARZELAY, Michael; ARMAJANI, Babak. Breaking through bureaucracy: a new vision for managing in government. Berkeley: University of California Press, 1992.

BILHIM, João. Cultura organizacional do INESC. Lisboa: ISCSP, (dissertação de mestrado), 1988.

. Para uma Teoria da Gestão da Mudança Estratégica. In:

Estratégia e planeamento na gestão e administração pública. Lisboa: ISCSP, 1995.

. Gerir a Administração Pública como uma Empresa. In: Reforma do estado. Lisboa: ISCSP, 2000.

. Teoria organizacional: estruturas e pessoas. Lisboa: ISCSP, 2008.

. Ciência da administração. Lisboa: Universidade Aberta, 2008.

BJUR, Wesley; CAIDEN, Gerald. On Reforming Institutional Bureaucracies. International Review of Administrative Sciences, Brussels/Belgium, v. 44, p. 359-65, 1978.

BURNS, Tom; STALKER, George MacPherson. The management of innovation. London: Tavistock, 1961.

CARVALHO, Elisabete Reis. Reengenharia na administração pública: a procura de novos modelos de gestão. Lisboa: Instituto Superior de Ciências Sociais e Políticas, 2001.

CUNHA, Miguel Pina; REGO, Arménio. O Tao da Mudança: mudança organizacional desestruturadamente estruturada. In: COSTA, S. G.; VIEIRA, L.; RODRIGUES, J. N. Gestão da mudança. São Paulo, Atlas, 2009.

FERRAZ, David Alexandre. A seleção de dirigentes públicos no contexto da evolução do estado e da administração: contributos para uma definição de uma política integrada. Dissertação de Mestrado em Administração e Políticas Públicas, ISCTE, 2008. 
GREGORY, Robert. All the King's Horses and All the King's Men: Putting New Zealand's Public Sector Together Again. International Public Management Review, St. Gallen/Switzerland, v. 4, n. 2, p. 41-58, 2003.

HART, Paul; WILLE, Anchrit. Ministers and Top Officials in the Dutch Core Executive: Living Together, Growing Apart? Public Administration, v. 84, n. 1, p. 121-146, 2006.

HOOD, Christopher. The new public management in the 1980s:

variations on a theme. Accounting, Organizations and Society, Oxford/ UK, v. 20, n. 2-3, p. 93-109, 1995.

KETTL, Donald. The Global Public Management Revolution. Washington: Brookings Institution Press, 2000.

MOZICAFREDO, Juan. O Papel do Cidadão na Administração Pública. In: Reforma do Estado e administração pública gestionária. Lisboa: ISCSP, 2000.

OLSEN, Johan. P. Modernization Programs in Perspective: Institutional Analysis of Organizational Change. Governance: An International Journal of Policy and Administration, Malden/USA, v. 4, n. 2, p. 12549, 1991.

POLLITT, Christopher. Convergence: the useful myth? Public Administration, v. 79, n. 4, p. 933-47, 2000.

POLLITT, Christopher; BOUCKAERT, Geert. Public Management Reform: a comparative analysis. Oxford: Oxford University Press, 2000. POLLITT, Christopher; HOMBURG, Vincent. The new public management in Europe. Palgrave: Macmillan, 2007.

PORTUGAL. Programa de reestruturação da administração central do estado (PRACE). 2006.

. Plano de redução e melhoria da administração central do estado (PREMAC). 2011.

ROCHA, José Antonio Oliveira. Gestão pública e modernização administrativa. Oeiras: INA, 2009. 
WEBER, Max. Economy and society. California: University of California City, 1978. 